\title{
De la Beneficiencia a la reforma social. Los orígenes de la política social del Estado: estado de la cuestión, fuentes y archivos
}

\author{
Feliciano Montero *
}

\section{DE LA BENEFICIENCIA A LA POLITICA SOCIAL}

El título de la ponencia -De la beneficiencia a la política social-sugiere deliberadamente un lento proceso de cambio en la mentalidad, las leyes, las politicas y las instituciones administrativas. Se alude a un tiempo más o menos largo de transición, en el que aparecen a menudo mezclados los criterios antiguos de la política asistencial con los nuevos de la política social. Pues, en general, los inicios de la política social (o del Estado del bienestar) se plantean sobre la base de la política e instituciones preexistentes, que coexisten durante bastante tiempo con las nuevas. La transición del estado liberal al Estado social intervencionista, está acompañada por otra transición no menos significativa, en el terreno mental y en el institucional: de la beneficiencia a la previsión. Se trata de un periodo bastante largo, que por lo menos coincide con el largo período de la Restauración, aunque podamos introducir una periodización significativa.

Dos buenas visiones de conjunto sobre esta evolución en España, que comenzaron a llenar un poco la laguna historiográfica, son los libros colectivos, Cuatro siglos de acción social. De la beneficiencia al bienestar social, (1986), publicación de las actas de un seminario convocado por el Consejo General de asistentes sociales, en diciembre de 1984, que reunió a modernistas y contemporaneistas estudiosos de los hospitales, la beneficiencia, la medicina social, y los seguros sociales... Y la Historia de la acción social pública en España. Beneficiencia y Previsión (1990), proyecto surgido del

* Dpto. $H^{a}$ Contemporánea, Uned, Madrid 
seminario anterior y coordinado por Alvarez Junco. Tras una referencia al Antiguo Régimen, las colaboraciones se enmarcan en tres grandes etapas: "El estado liberal, asistencia y control" (hasta 1900); "Hacia el Estado intervencionista: Previsión y Beneficiencia» (hasta 1936); "Intervencionismo y Estado franquista".

En relación con la Beneficiencia, recientes estudios, como el de Pedro Carasa, han trazado bien la evolución desde la beneficiencia del Antiguo Régimen a la beneficiencia pública del Estado liberal. El mismo autor presentó en el Congreso de historia social de Zaragoza (septiembre 1990) una buena revisión historiográfica de los estudios sobre instituciones benéficas '.

Pero en España, los estudios sobre beneficiencia se han centrado más en la crisis del Antiguo Régimen y la primera etapa liberal, que en esa otra etapa de transición hacia la previsión social y los seguros sociales, que es precisamente la que aquí nos interesa más. Las manifestaciones esencialmente ambiguas, en el terreno mental, ideológico, administrativo y político, de esa fase de transición son abundantes.

Un reciente artículo de $A$. Shubert ha señalado algunos hitos ideológicos importantes de esa transición siguiendo los planteamientos de algunos publicistas como Concepción Arenal... La tesis de Mariano Esteban de Vega, "De la Beneficiencia a la Previsión, la acción social en Salamanca (18751898)" se plantea precisamente, esa fase de transición ideológica y mental que tiene su reflejo en el plano institucional y en el de las iniciativas reformistas concretas ${ }^{\text {? }}$.

El profesor de derecho del trabajo Alfredo Montoya Melgar, desde el análisis textual de los preámbulos de las primeras leyes socio-laborales, ha insistido en la pervivencia de la mentalidad asistencial y benéfica en el legislador incluso en el período 1917-1923 ${ }^{3}$.

Vid. su tesis sobre Burgos, Pauperismo y revolución burguesa (Burgos 1750-1900) Valladolid 1987, y El sistema hospitalario español en el siglo XIX. De la asistencia benéfica al modelo sanitario actual, Valladolid, 1985 y el estado de la cuestión presentado en el Congreso de la Asociación de Ha Social, Zaragoza, Metodologia del estudio del pauperismo en el contexto de la revolución burguesa española: Santiago Castillo (coord.) "la Historia social en España. Actualidad y perspectivas", ed. Siglo XXI, 1991.

2 Nosotros mismos hemos esbozado esta cuestión en los primeros capítulos del $1^{\circ}$ vol. de la historia de los seguros sociales ed. $\mathrm{M}^{\circ}$ Trabajo... La tesis de M. Esteban publicada por ed. Diputación. Salamanca, 1991; el artic. de A. Shubert: Nuevos enfoques sobre la beneficiencia en la España del siglo XIX "Studia Zamorensia" 5 (1984) 325-336.

3 Vid. Montoya Melgar, A. Tres trabajos con el título genérico, "ldeologia y lenguaje en las leyes laborales...", en la primera legislación social, en la crisis de la Restauración, 1917-23, y en la dictadura de Primo de Rivera. 
En la abundante publicística de la época sobre la cuestión social, el pauperismo, las instituciones benéficas, etc, que se genera, especialmente en el último cuarto del siglo XIX, en Ateneos, Academias, Círculos Mercantiles, con motivo de las inauguraciones de curso, o con ocasión de concursos y debates directamente patrocinados por esas instituciones, se puede rastrear esa lenta transición mental de la conciencia benéfico-caritativa a la nueva conciencia social, las pervivencias y los cambios.

En el plano de las instituciones públicas se aprecia bien la pervivencia de conceptos y tratamientos «viejos» para las nuevas cuestiones sociales: la Información oral y escrita de 1884 dedicaba una parte de su cuestionario al estudio de la Beneficiencia. La información estadística sobre la beneficiencia en España a principios de siglo (en 1909, 1913, y 1917-19) seguia considerando las instituciones de ahorro y previsión como instituciones benéficas ${ }^{4}$.

Paralelamente al IRS, en el seno de la Sección española de la Asociación internacional para la protección legal de los trabajadores surgieron instituciones como, la Sociedad española contra el alcoholismo, la Liga antipornográfica, el Comité Español de Tribunales para niños... que se inscriben más en la órbita de los viejos objetivos benéficos y morales que en los propiamente sociales.

La protección del niño trabajador fue objeto primero y preferente de la legislación social española, pero la protección de la infancia abandonada recibió un tratamiento específico en el conjunto de la política asistencial del Estado, especialmente a partir de la creación del Consejo Superior de Protección a la Infancia ${ }^{5}$.

En cuanto a las iniciativas privadas, la memoria del católico barcelonés Ramón Albó es un testimonio elocuente de la vitalidad de la iniciativa caritativa benéfica a principios de siglo, en una ciudad industrial como Barcelona, donde los nuevos problemas sociales seguian recibiendo un tratamiento prioritariamente benéfico-caritativo, aunque también se plantearan nuevas iniciativas sociales como la Caixa de Pensions ${ }^{6}$.

4 Vid. Marin de la Barcena, A. Apuntes para el estudio y la organización en España de las instituciones de beneficiencia y previsión. Madrid, 1909; y actualizaciones sucesivas hasta 1918.

5 Para el estudio de la actividad del Consejo Superior y de las juntas provinciales vid. "Pro infancia" (1909-1929) Boletín del Consejo; y las actas de la 1a Asamblea nacional de protección a la infancia". Madrid 1914, 2 vols. Entre los proyectos preparados por la CRS hay uno relativo a los "Niños dedicados habitualmente a la mendicidad o abandonados por sus padres".

6 Sobre la Caixa de Pensions y su fundación, vid. J. Nadal y C. Sudria... Historia de la Caixa de Pensiones, Barcelona, 1981 y el libro de Alfred Pérez Bastardas Francesc Moragas i Barret i la Caixa de Pensións (1868-1935), ed. servei d'Estudis de la Caixa, junio 1990; sobre las iniciativas 


\section{LOS ORIGENES DE LA POLITICA SOCIAL DEL ESTADO}

Conviene tener en cuenta la amplitud creciente del concepto de política social. Ya en la época, el discurso de J. Canalejas en 1905 en la Academia de Jurisprudencia de Madrid, "La obra social contemporánea», nos ofrece una visión muy amplia de las múltiples facetas que debía adoptar la reforma social: no sólo la regulación de las condiciones de trabajo (leyes laborales que configurarán un nuevo código, el Código del trabajo), sino la municipalización de ciertos servicios públicos, o ciertas reformas fiscales y hasta de procedimiento judicial.

La politica social del Estado se va a desarrollar y concretar principalmente en tres grandes campos:

- el de la regulación de las condiciones del trabajo, mediante el nacimiento de una serie de leyes protectoras que llegarán a configurar el nuevo Código del Trabajo.

- el de la previsión social o seguros sociales: aplicación del principio técnico, actuarial, de las compañias de seguros, a las condiciones de la vida popular, en coexistencia pero tendiendo a sustituir otras formas de previsión "empíricas", como el socorro mutuo.

- el de unas nuevas instituciones administrativas, destinadas a gestionar los nuevos derechos sociales (el Instituto Nacional de Previsión y el Instituto de Reformas Sociales).

Una de las facetas del crecimiento del Estado moderno es precisamente ese creciente intervencionismo social que desemboca en el "Estado del bienestar». La reciente crisis de ese modelo de Estado asistencial, a partir de los setenta, ha fomentado el estudio y el debate sobre los orígenes, el auge y la crisis del "welfare state".

El estudio del reformismo social se sitúa pues en un plano interdisciplinar. El tema interesó inicialmente, desde una perspectiva más reducida, a los laboralistas y de profesores del derecho del trabajo, en la búsqueda de los orígenes de su propia disciplina. Pero es del campo de la sociología y la ciencia política, más que del de las ciencias jurídicas del que proceden las más recientes e interesantes contribuciones. La previa investigación empírica del desarrollo legal e institucional de la legislación social y de la

asistenciales católicas en Barcelona vid. J. Romero Maura "La rosa de fuego" C. Winston "La clase trabajadora y la derecha en España, 1900-1936, ed. cátedra, 1989, cap. 1 «El tracaso social de la élite católica catalana”. Ios libros de R. Albó, La caridad en Barcelona, 1901, y Barcelona caritativa y benéfica, 1914. 
De la Beneficiencia a la reforma social. Los origenes de la política social...

seguridad social en los diversos paises europeos, ha permitido el planteamiento de estudios comparativos sobre los diversos sistemas, como el estudio modélico de $\mathrm{P}$. Flora y J. Alber sobre «El desarrollo de los Welfare State y los procesos de modernización y democratización en la Europa occidental» ${ }^{7}$. Dicho estudio cuestiona la hipótesis, generalmente admitida, de la estrecha relación de dependencia entre el proceso de modernización (grado de desarrollo económico y nivel de urbanización), el nivel de movilización política, especialmente obrera, como factor de presión, y el origen y desarrollo legal e institucional del Estado del bienestar. Proponiendo precisamente distintos modelos según los distintos tipos de desarrollo político ${ }^{8}$.

- Sin dejar de ser un tema preferentemente interdisciplinar y de especial interés de politólogos y sociólogos, la historiografia internacional lo ha asumido oficialmente, como revela su presencia destacada en los últimos congresos internacionales de historia. Tanto en el congreso de Sttugart (1985), como en el de Madrid (1990), la política social del Estado y el Estado del bienestar recibió un tratamiento específico ${ }^{9}$.

En España el estudio de los orígenes del “estado del bienestar» es mucho más reciente, pero finalmente, en la coyuntura conmemorativa del centenario de la Comisión de reformas sociales, los historiadores lo han asumido como objeto específico de investigación.

También aquí las primeras referencias se encuentran en los estudios de los profesores de derecho del trabajo (especialmente De la Villa, Palomeque, Montoya Melgar). Apenas, sino muy recientemente, los sociólogos y politólogos han entrado en el debate internacional sobre la crisis del «Estado del bienestar». $Y$ al hacerlo, apenas se han referido a los

Vid. FLORA, P. y ALBERT, J. Sviluppo dei Welfare States e processi di modernizazione e democratizaziones nell' Europa occidentale en FLORA, P. y HEIDENNHEIMER, A. LO sviluppo del welfare state in Europa e in America, ed. II Mulino, 1983 (1 ${ }^{\text {a }}$ edic. ingl. 1981).

8 Douglas E. AsHFORD en La aparición de los Estados de bienestar, Madrid $1989 \mathrm{M}$. Trabajo (1986, $1^{\text {a }}$ ed.), insiste en la necesidad del estudio institucional y político. El análisis histórico pone de relieve las peculiaridades de cada pais en la transformación del Estado liberal en el social democrático. Las particularidades de cada proceso de democratización (el inglés, francés, alemán, sueco, norteamericano), explican, a la vez que influyen en su peculiar modelo de Estado del bienestar.

9 Vid. ponencia de G.A. RITTER, sobre el tema "Politique sociale au XIX et XX siècles" en la sección de $\mathrm{H}^{\underline{a}}$ Contemporánea del XVII Congreso Internacional de Ciencias Históricas, y comunicaciones sobre Francia, Gran Bretaña, Italia, Polonia, España, Alemania, Estados Unidos y URSS. Vid. también las conferencias de G.A. Ritler en la Universidad de Salamanca sobre "Los comienzos y el desarrollo del Estado social en Alemania, Europa y Estados Unidos hasta la $2^{a}$ Guerra mundial", y "La Seguridad Social y las relaciones laborales en Europa desde la $2^{a}$ guerra mundial hasta nuestros dias", publicadas en "Studia Histórica", VIII (1990), y su obra "El Estado social, su origen y desarrollo en una comparación internacional, ed. Mº Trabajo, Madrid, 1991. 
orígenes y antecedentes históricos, quizá, en parte, por la ausencia, hasta muy recientemente, de investigaciones empíricas, descriptivas sobre ese proceso histórico.

El retraso español en el tratamiento historiográfico del tema del reformismo social puede deberse a diversas razones: por una parte el propio retraso del objeto o realidad histórica, pues la guerra civil trunca un proceso aún muy incipiente. Por otra parte, la política social del franquismo es ponderada inicialmente de forma exclusivamente apologética, para ser después menospreciada o ignorada. El tema del reformismo social y la política social del Estado, quizá por sus vinculaciones ideológicas y políticas con el conservadurismo, el catolicismo social, el nacional-sindicalismo y el nacional-catolicismo, es tan descuidado por la historiografía de los años 60 y 70 como, en general, el estudio de la derecha y de los conservadores.

Antes de la década de los 80 , las aproximaciones españolas al tema del reformismo social se habían hecho predominantemente desde la perspectiva del derecho laboral (el estudio de antecedentes), o desde la perspectiva ideológica. Ahora bien, en este último caso, ello se hacía reivindicando el protagonismo exclusivo de la familia krausista-institucionista en la fundación y desarrollo de las primeras instituciones social-reformistas, Comisión de Reformas Sociales (CRS) e Instituto de Reformas Sociales (IRS).

En la década de los 80 , investigaciones impulsadas por la conmemoración del centenario de la Comisión de reformas sociales, han permitido un conocimiento más matizado y completo. En muy pocos años, nuestro conocimiento de los orígenes del «Estado del bienestar» en España, y de las primeras instituciones reformistas del Estado, la Comisión, el Instituto de Reformas Sociales y el Instituto Nacional de Previsión, ha aumentado notablemente.

Basta remitirse a las publicaciones del $\mathrm{M}^{\circ}$ de Trabajo: los volúmenes de la Información oral y escrita, el informe y proyecto de Canalejas sobre el Instituto del Trabajo, el libro de $\mathrm{M}^{\mathrm{a}}$ Dolores de la Calle sobre la Comisión (CRS), el de J.I. Palacio sobre el IRS ("La institucionalización de la reforma social en España»), y la obra conjunta dirigida por M.D. Gómez Molleda sobre los "Seguros sociales en la España del sigio XX". Esta última obra es la primera aproximación de conjunto, y esa es su principal valor como punto de partida para investigaciones posteriores. Aunque el hilo argumental y la base documental del estudio es el Instituto Nacional de Previsión, no se queda en un mero análisis institucional o legal, sino que se plantea desde la caracterización del equipo fundador y dirigente ( $M$. Samaniego subraya el pluralismo), hasta las posiciones de los distintos grupos sociales y económicos ante la implantación de los distintos seguros sociales (cuestión en la que insiste sobre todo $\mathrm{J}$. Cuesta en su volumen). Lamentablemente no se aprovecha suficientemente la bibliografía europea, ni esa perspectiva teórica y comparativa 
del trabajo de P. Flora al que antes aludiamos, a pesar de los intentos, especialmente de J. Cuesta en el capítulo introductorio de su volumen.

Las publicaciones del $\mathrm{M}^{\circ}$ de Trabajo no se han limitado a esta edición de investigaciones españolas, sino que está facilitando el estudio comparativo del tema mediante las traducciones de clásicos (los informes de Bedveridge) y de estudios actuales como el de Douglas E. Ashford sobre "La aparición de los estados del bienestar» o el de G. Ritter "E! Estado social, su origen y desarrollo en una comparación internacional".

Así pues la bibliografía española citada, nos ofrece ya un marco de referencia suficiente, para abordar estudios monográficos parciales e investigaciones regionales o locales, y nos permite una periodización de la política social, que se inserta bien, tanto en la evolución europea, como en el contexto político español:

- antecedentes: el tiempo de la CRS, desde las primeras reflexiones sobre la cuestión social suscitadas por los acontecimientos del sexenio liberal-democrático y la Comuna de Paris (1871), hasta la publicación de la Información oral y escrita y la reorganización de la CRS (1890)

- una fase de maduración mental, progresiva concienciación, y elaboración de bases legislativas, y proyectos de ley; a la vez que de incorporación progresiva de los actores sociales, patronos, obreros, en las instituciones reformistas. Es el tiempo del IRS, y la primera fase del INP, aproximadamente desde 1891 hasta 1917.

- La crisis social y política de la Restauración (1917-1923), coincidente con la crisis europea de la postguerra, parece acelerar los impulsos reformistas: reforma del IRS, nuevas leyes sociales sobre la jornada laboral, implantación del primer seguro obligatorio (el seguro de vejez). La desaparición del IRS y su progresiva sustitución (tras una primera integración) por el $\mathrm{M}^{\circ}$ de Trabajo tiene un significado ambiguo. Pues la creación del Ministerio parecía reconocer mayor y definitivo rango a la política social, integrando competencias administrativas dispersas en un nuevo ministerio, y superando la vinculación tradicional de la cuestión social con las de orden público en el Ministerio de Gobernación. Pero, por otra parte, con el IRS desaparecía un organismo autónomo, que habia demostrado una notable independencia administrativa junto a una gran capacidad de arbitraje neutral entre las partes confrontadas. La representación obrera, siempre monopolizada por los socialistas, tenía en el IRS una buena plataforma de presión, que resultaría molesta a los patronos ${ }^{10}$.

10 La mejor sintesis sobre el IRS, J.I. PALACIO, La institucionalización de la Reforma Social en España (1889-1924). La Comisión y el Instituto de Reformas Sociales, ed. Mà Trabajo, 1988; sobre 
- la dictadura primorriverista y la $2^{\text {a }}$ república imprimen su sello particular, aunque dentro quizás de continuidades fundamentales. Continuidades en las personas (el equipo dirigente del INP) y en los objetivos. Aunque el organicismo liberal-democrático de los krausistas del IRS, difiera del corporativismo católico de los colaboradores de Primo de Rivera, o del reformismo social-demócrata del ministro Lago Caballero. Diferencias que no implican incompatibilidades.

Sobre la política social de la dictadura de Primo de Rivera algunos estudios recientes superan la mera crítica "a priori». Según Palacio Morena, la disolución del IRS y su sustitución por el Consejo de Trabajo, había supuesto el abandono del impulso social-reformista presente en el IRS desde su fundación. Pero el malestar de los patronos con el funcionamiento de los comités paritarios y la importante presencia de los socialistas en ellos parecen significar la validez y operatividad de esa política corporativista ${ }^{11}$.

En cuanto a la $2^{a}$ República, reconociendo una mayor decisión política y un tono menos paternalista, la política social desde el Ministerio que desempeñaba Largo Caballero, era en buena medida la continuación de proyectos reformistas anteriores impulsados desde el IRS. En el INP, según la sintesis de M. Samaniego, se observa tanto en el equipo dirigente como en los proyectos una continuidad fundamental junto a impulsos renovados. En todo caso faltó tiempo para desarrollar nuevas políticas como el proceso de unificación de los seguros sociales.

- Tras el paréntesis de la guerra civil, el franquismo constituye en sí mismo un período bien definido. La seguridad social como conjunto sistemático y unificado de seguros sociales surge en este período. Y más allá de prejuicios o tópicos ideológicos deberá ser estudiado, en el marco comparativo de otros desarrollos europeos.

\section{Algunas cuestiones en perspectiva comparativa}

Pero la reciente y creciente bibliografía española sobre el tema adolece, en general, de esta necesaria perspectiva teórica y comparativa a la

\footnotetext{
la creación del $\mathrm{M}^{a}$ Trabajo y la disolución del IRS, pp. 107-138, “La creación del Ma de Trabajo refleja la ambigüedad del contexto social en que nace. Supone, en abstracto, un paso relevante en la modernización del aparato institucional. En la práctica, se revela más como un elemento de freno en la participación social y de repliegue institucional, que como un factor de racionalización y perfeccionamiento democrático" p. 125.

11 Vid. Gomez Navarro, J. El régimen de Primo de Rivera, Barcelona, 1991.
} 
que nos referiamos más arriba. Un punto de partida como el que ofrece el estudio de $\mathrm{P}$. Flora, puede servir para revisar ciertos tópicos sobre los origenes del Estado del bienestar en la España de la Restauración, como lo ha hecho Ana Guillén, del Centro de Estudios Sociales de la Fundación March, que se ha servido de ese planteamiento en su artículo "The emergence of the Spanish Welfare State. The role of ideas in the policy process", y en su proyecto de investigación sobre Políticas de salud y reforma institucional en España: un análisis comparativo en el caso italiano" ${ }^{12}$.

\section{La cuestión del retraso}

Una cuestión siempre recurrente, cuando se acude a la perspectiva comparativa, es la del retraso español. Esta es la queja y el argumento reiterativo utilizado por los mismos propagandistas y «sociólogos» para impulsar la reforma social en España. Ciertamente hay ejemplos suficientes de ese retraso. Cuando en España se fundaba el INP con el objetivo de impulsar la propaganda de la previsión social en el régimen de "libertad subsidiada", el Congreso internacional de Roma de seguros sociales (1908) había aprobado el régimen obligatorio de seguros sociales como el más recomendable. Sin embargo la referencia al retraso responde sobre todo a la retórica generacionista tan en boga. En la perspectiva comparativa del estudio de P. Flora, y según subraya $A$. Guillén, el retraso español, al menos hasta la guerra civil, no es tan importante como habitualmente se ha señalado. Las principales leyes laborales (ley de accidentes de trabajo 1900), y los primeros hitos de los seguros sociales se implantan con un ritmo y unas caracteristicas muy análogas a la de la mayoría de los países europeos. Sólo la guerra civil, como en otros muchos terrenos, impone un paréntesis, que implica un retraso importante respecto al momento de gran desarrollo de la seguridad social en la postguerra.

\section{¿Un impulso de élites o una demanda popular inexcusable?}

Generalmente se ha tendido a considerar el surgimiento y el desarrollo del "Estado del bienestar» como directamente ligado al conflicto social; como respuesta inexcusable a una demanda obrera organizada. Las propias organizaciones socialistas han propagado esta idea considerando las reformas sociales como "conquistas obreras", concesiones del Estado

12 Ana GUILLEN. The emergence of the Spanish. Welfare State: The Role of Ideas in the Policy Process Madrid, 1989, Centro de Ciencias Sociales del Instituto Juan March. 
capitalista. Esta concepción de los protagonistas se ha proyectado con frecuencia en la visión de los historiadores, olvidando el verdadero peso político, y la fuerza real de presión del movimiento obrero. La reciente revisión historiográfica de la historia del movimiento obrero ha corregido en buena medida esa visión de un movimiento extendido y poderoso. Paralelamente también se ha corregido una visión demasiado simplista y unitaria de la patronal como un bloque homogéneo y reaccionario, social y políticamente.

Desde esta perspectiva, la primera fase del reformismo social en España, podría deberse más al voluntarismo y la iniciativa de unas élites intelectuales, bien informadas de la reflexión y las experiencias europeas. Las propuestas de estas élites y los proyectos sociales irian por delante de la demanda social e incluso de la realidad económica de un país aún poco industrializado. Lo que podría explicar la amplitud de las resistencias, no sólo patronales, a la aplicación, por ejemplo, de la ley de descanso dominical; o la ignorancia y resistencias a la aplicación de una ley tan «moderna" como la de accidentes de trabajo de 1900.

El análisis del caso español confirma una de las tesis centrales del citado artículo de P. Flora: no hay una relación, directa entre grado de modernización y surgimiento del welfare state. Al menos antes de la primera guerra europea, ni el grado de desarrollo económico, ni la presión obrera pueden explicar el nacimiento de las primeras instituciones públicas (IRS e INP). Otra cosa sería la etapa en que se comienza a implantar el retiro obrero obligatorio o se regula la jornada laboral mínima (1919). Período que coincide efectivamente con un importante auge económico, y con un fuerte crecimiento de la demanda obrera organizada y de la movilización política en general (la crisis social y política de la restauración 19171923).

Así pues, descartados los factores de modernización y de movilización, los orígenes de la política social en España, en la primera década del siglo $X X$, sólo pueden deberse al importante papel jugado por una élite intelectual, políticamente influyente y relativamente independiente de los grupos de intereses. Eso mismo explicaria el hecho de que la politica social surja al margen de las disputas político-electorales, en un terreno neutral, más técnico que político, en el que es posible la convergencia y la colaboración de hombres de procedencia ideológica y militancia política distinta. Uno de las características más señaladas en los estudios sobre el IRS y el INP es el que constituyan lugares de encuentro y de colaboración (a veces también de confrontación) de «Institucionistas», católicos y socialistas. 


\section{ALGUNAS PROPUESTAS DE INVESTIGACIÓN: NOTICIA SOBRE FUENTES Y ARCHIVOS}

Las propuestas que se presentan nacen de la consideración previa sobre el estado de la cuestión, y tienen en cuenta la posibilidad de explotar nuevas fuentes que deberán (o deberian) estar depositadas en los archivos públicos, de la administración central, provincial y municipal.

Para completar el marco general de referencias, partiendo de las contribuciones ya existentes, se deberian precisar y concretar más algunos perfiles sobre el proceso de implantación legal e institucional, y sobre todo el grado de aplicación y desarrollo de la legislación social y de los seguros sociales. Para ello sería muy conveniente utilizar más de lo que hasta ahora se ha hecho la perspectiva comparativa. Igualmente, para responder a la cuestión del grado de aplicación e implantación se impone insistir en la investigación local y regional. La deficiente conservación de las fuentes de la administración central hace indispensable, por otra parte la búsqueda en los archivos locales.

Todavía queda bastante por estudiar, aunque quizás es de lo que más sabemos, sobre el nivel de difusión de las nuevas ideas en Círculos, Ateneos, la prensa, etc. Apenas se ha estudiado tampoco la influencia indudable de las ideas, proyectos y modelos extranjeros en la elaboración de los proyectos españoles.

En el contexto del estudio de las élites, tema en auge en la historiografía actual, valdría la pena identificar a nivel local los principales impulsores y protectores de diversas iniciativas benéficas y sociales. El nacimiento de las Cajas de ahorro, muy estudiado, pone de relieve esa participación. Pero también es decisiva, por ejemplo, en el apoyo a otras instituciones de previsión como las Sociedades de Socorro Mutuo ${ }^{13}$.

\section{Movimiento obrero, Politicas patronales y politica social}

Habitualmente se ha tendido a establecer una estrecha relación entre el movimiento obrero, la conflictividad social, y las respuestas reformistas, patronal y estatal. A pesar de lo cual son escasos los numerosos estudios

13 Vid. F. MONTERO y M. ESTEBÁN. Aproximación tipológica al mutualismo popular y obrero en España. El mutualismo asistencial: Santiago Castillo (coord.) "La Historia social en España»1991, pp. $457-470$. 
del movimiento obrero que han tenido en cuenta esta perspectiva: el estudio de los otros protagonistas del conflicto social.

Los estudios sobre relaciones laborales, industriales, y las estrategias y políticas patronales son aún escasos, pero ya disponemos de algunos estudios importantes: a los pioneros de Olavarri sobre relaciones laborales en Vizcaya o de Mercedes Cabrera sobre la patronal en la $2^{\text {a }}$ república, o el estudio posterior de $A$. Shubert sobre Los orígenes de la revolución de Asturias, que contiene un excelente capítulo sobre la política social de Comillas en el coto minero de Aller, hay que añadir las recientes tesis doctorales, de Fernando del Rey y de Soledad Bengoechea 14. El estudio del conflicto social como lugar de confrontación de los distintos protagonistas, tiene un gran interés desde el punto de vista de la investigación.

Bajo el concepto de "sociabilidad" se están haciendo algunas investigaciones que permiten una aproximación mucho más real al conocimiento de la condición de vida y mentalidad de las clases populares. Se trata de una línea de investigación, impulsada sobre todo, por hispanistas franceses: J. Maurice, M. Ralle, J.L. Guereña ${ }^{15}$.

\section{Los archivos y las fuentes}

Los Archivos de la Administración central han sido los más utilizados, aunque, probablemente todavía insuficientemente, para el tema de que tratamos.

En primer lugar hay que tener en cuenta que las vicisitudes y alternativas en el proceso de institucionalización de la administración social, tiene su reflejo en la dispersión "administrativa" de las fuentes. Hasta la creación del Ministerio de Trabajo (1920), tanto la CRS como el IRS y el INP dependian fundamentalmente del Ministerio de Gobernación, así como todo lo relacionado con beneficiencia y sanidad. Pero además, algunos servicios, como el de estadística del trabajo, la emigración, etc. dependian

14 Soledad BENGOECHEA: "Patronal catalana, corporativismo y crisis politica, 1898-1923", Barcelona, Un. Autónom, 1991; Fernando DEL REY "Organizaciones patronales y corporativismo en España (1914-1923)", Un. C. Madrid, 1989. Publicada con el título Propietarios y Patronos, Madrid, 1992, Ministerio de Trabajo. Vid. comunicación conjunta presentada en el Simposio sobre "La politica conservadora en la España contemporánea, 1868-1986", UNED, noviembre 1991, "En visperas de un golpe de estado. Radicalización patronal e imagen del fascismo en España".

15 Vid. $\mathrm{n}^{\circ}$ 50-51 de la revista "Estudios de Historia social». 
De la Beneficiencia a la reforma social. Los origenes de la politica social...

del Ministerio de Fomento, y de las Direcciones de Comercio, Industria, etc.

Hasta ahora no se han podido localizar los archivos específicos ni los inventarios de la CRS ni del IRS. La carencia es especialmente grave en relación con el IRS, a pesar de la abundante y rica información contenida en el Boletín y en las múltiples publicaciones del IRS: Memorias de Inspección de trabajo, estadísticas de accidentes de trabajo, huelgas, salarios y jornadas laborales ${ }^{16}$.

La ausencia de esos archivos centrales hace si cabe mucho más imprescindible la consulta de la documentación de las Juntas locales y provinciales de Reformas sociales, que deben encontrarse en los respectivos archivos municipales y provinciales, como algunas investigaciones locales han constatado. El papel fundamental que los alcaldes y gobernadores civiles juegan como presidentes de esas Juntas, concede especial interés a la correspondencia de estos con las autoridades y con los protagonistas del conflicto ${ }^{17}$.

Otro es el caso del Archivo del INP, que se conserva aún parcialmente en su antiguo edificio, actualmente sede del Insalud. En este caso, además de las publicaciones del INP y de su rica biblioteca, disponemos del archivo, sólo en parte explotado por la investigación del grupo de Salamanca sobre Los seguros sociales, o por alguna otra investigación en marcha sobre las Cajas de Previsión, colaboradoras del INP.

En el actual archivo del Insalud se conserva aún buena parte del fondo antiguo del INP: los libros de actas de las diversas comisiones:

Comisión delegada de la Junta de Gobierno, 1922-1935; Comisión de Informes, 1924-38; Comisión gestora del subsidio de maternidad, 1923-36; Comisión Revisora Paritaria Superior de previsión, que contiene la vista y resolución de recursos diversos planteados por patronos y empresas sobre indemnizaciones en aplicación de la ley de seguros de accidentes, 1934-38; de la Comisión Asesora Nacional Patronal y obrera, 1922-1930; del Consejo Nacional contra el paro forzoso, 1932-36; de la Comisión de Inversiones,

16 E! libro de J.I. Palacio, que lamenta la posible pérdida del archivo del IRS, presenta en apéndice una explicación detallada de la información contenida en las publicaciones del IRS. LO único que se conserva de la CRS y del IRS son algunos papeles sueltos en el AHN, sección de gobernación, y en el AGA de Alcalá.

Los libros de A. Soto Carmona y de J. Rodríguez Lavandeira sobre "el trabajo industrial" y "el trabajo rural», publicados por el Anthropos, utilizan abundantemente las publicaciones del IRS.

17 Una visión de conjunto de las reformas sociales en F. RuBio: Las Juntas de reformas sociales y el reformismo social en la Restauración, 1900-1924: “Espacio, Tiempo y Forma" 1 (1988) $\mathrm{H}^{\mathrm{a}}$ contemporánea. 
1933-37, de la Comisión de Accidentes de trabajo, 1932; de la Ponencia financiera, 1909-25; de la Mutualidad de la Previsión, 1927-36.

Para este mismo período se cuenta con Indice y Extractos de Acuerdos aprobados por la Comisión Gestora, Consejo de Patronato, Junta de Gobierno y Comisión de Informes. Estos índices suponen un vaciado sistemático de los libros de actas correspondientes.

Otro bloque lo constituyen los libros de actas de las Cajas Colaboradoras (se conservan todas salvo las de Cataluña y el País Vasco), fuente complementaria para el estudio local y regional de la real implantación de los seguros sociales en cada territorio. Pues en las propias Cajas se encontrará el grueso fundamental de la documentación correspondiente a esta etapa ${ }^{18}$.

De la etapa de la guerra civil se conservan los libros de actas de las dos instituciones paralelas: del Consejo de Patronato y la Junta de gobierno (zona republicana), y de la Comisión Nacional de Previsión Social, que funcionó en Santander entre septiembre del 36 y julio del 38.

En el mismo archivo se conservan también los libros de actas de los organismos dirigentes del INP en la primera etapa franquista, tras la etapa provisional 1936-38: del Consejo y de la Comisión Permanente, de la de Obras, del Tribunal de Oposiciones, y de las diversas Ponencias y Comisiones encargadas de preparar las reformas de 1943-44; y de la Ponencia sobre el seguro de enfermedad (1948-52) ${ }^{19}$.

Como se ve, esta documentación, fundamentalmente libros de actas constituye sólo una parte de la documentación administrativa, económica, correspondencia, etc. que debería haberse conservado. Sólo sobre las Mutualidades Escolares se conserva un fondo específico. (Es probable que otra mucha documentación se haya perdido).

Toda esta documentación, de carácter claramente histórico, y totalmente ajena al actual Insalud, sólo parcialmente heredero del antiguo INP,

18 Un ejemplo es el Archivo de la Caixa de Pensions de Cataluña, bien organizado a partir de la investigación de Sudriá-Nadal sobre la Historia de la Caixa (1981); archivo también utilizado por Alfred Pérez Bastardas en Francesc Moragas i Barret i La caixa de Pensions, Barcelona, 1990.

19 El estudio colectivo sobre "Los seguros sociales en España" dirigido por la Pra. Gómez Molleda ed. $\mathrm{M}^{\circ}$ Trabajo. 3 vols. llega hasta 1936; una comunicación de $\mathrm{M}$. Samaniego al XVII Congreso Internacional de Ciencias Históricas de Madrid (agosto 1990), se refiere a la etapa de la guerra civil. Para el periodo franquista no disponemos de un estudio crítico. Un resumen útil de la evolución del INP en el primer franquismo, a pesar del tono triunfalista, es la memoria de Luis Jordana de Pozas, Los seguros sociales en España de 1936-1950, informe sobre las actividades y resultados de la gestión del Instituto Nacional de Previsión..., presentado en 1953, en la I Asamblea general del INP. En este informe Jordana señala cuatro etapas: la de transición o de suplencia, 1936-38; la de 1939-45, caracterizada "por una fuerte y jerárquica organización de gerencia; el periodo 1945-50 marca una tendencia al "predominio de los órganos colegiados». 
cuya conservación se debe al celo personal de los funcionarios "históricos" vinculados a la vieja casa, debería ser trasladada y catalogada convenientemente en el AGA.

Pero además de los fondos documentales reseñados, la biblioteca del INP y especialmente el fondo de publicaciones del Instituto, contiene información muy completa y aprovechable para el estudio de las personas (necrológicas, actos de homenaje), el marco legal y reglamentario, las discusiones y debates que suscitan la preparación de los diversos seguros (Conferencias de Previsión Popular, Conferencia de seguros sociales de 1917, Conferencia de Seguros de enfermedad, invalidez y maternidad, en Barcelona 1922); la divulgación popular y propagandista de los objetivos del INP (diversos folletos de gran tirada), los balances económicos, etc. A ello hay que añadir las publicaciones periódicas editadas por el propio INP en sus diversas fases: "Anales del INP", desde su fundación, la «Revista de la Mutualidad Escolar», y la «Revista Médico-Social» (hasta 1936); la revista «Previsión Social» (1942-46) y la «Revista Española de Seguridad Social» (desde 1947) 20.

Aunque todo lo relacionado con los seguros sociales haya que buscarlo principalmente en las publicaciones y el archivo del INP, hay que tener en cuenta la competencia de otros organismos, como la Dirección o Asesoría general de seguros, que en aplicación de la ley de accidentes de trabajo de 1900 , intervenia en el registro e inspección de Compañia de seguros privadas que contrataban con los patronos la cobertura de dicho seguro.

A partir de la creación del Ministerio de Trabajo (1920) y sobre todo, tras la desaparición del IRS (1924), hay que tener en cuenta los fondos específicos de ese ministerio, especialmente durante la etapa republicana, así como los fondos de Presidencia de Gobierno, durante la dictadura de Primo de Rivera en el Archivo Histórico Nacional.

Apenas se ha estudiado la influencia extranjera en la gestación del modelo español, aunque tanto las fuentes impresas como algunas documentales poco conocidas, depositadas en el archivo del Ministerio de Asuntos Exteriores permitirian estudiar sistemáticarnente esas influencias.

- Los libros de los propagandistas y reformistas españoles están llenos de referencias, sobre todo francesas, como se puede apreciar, por

20 Vid. Catálogo de publicaciones del INP, (1959) y anexo I (1962), y "Treinta y ocho años de doctrina de previsión y seguros sociales" catálogo bibliográfico de los estudios artículos doctrina. les y de información aparecidos en las publicaciones periódicas del INP, recopilado y ordenado por F. Gutiérazz Alamillo, Madrid, 1947. 
ejemplo, en los discursos académicos de Dato o Canalejas, pero también inglesas y alemanas. En fecha muy temprana uno de los fundadores del IRS, Adolfo Buylla publicó un balance muy completo de la legislación social internacional. Las publicaciones periódicas especializadas tanto españolas como extranjeras son una fuente imprescindible para este estudio. Del mismo modo, las crónicas de los congresos internacionales de accidentes de trabajo, seguros sociales, etc. permiten valorar la presencia española en esos foros ${ }^{21}$. Posteriormente, la creación de la sección española de la Asociación Internacional para la Protección legal de los trabajadores, presidida por Pedro Sangro permite seguir más de cerca la integración española en el contexto ideológico y legal de la reforma social. Un tema de especial interés en este terreno comparativo sería el estudio de las relaciones hispanoamericanas ${ }^{22}$.

Apenas se conoce la existencia de algunos fondos relacionados con los orígenes de la política social en el Ministerio de Asuntos Exteriores: aquellos estudios e informes que directamente se recababan de las embajadas españolas en el extranjero a la hora de buscar ejemplos y modelos de legislación social sobre diversos temas.

Desde los primeros pasos de la reforma social, en el tiempo de la Comisión de Reformas Sociales, se solicitan informes sobre la legislación social en Europa. En el AHN, Gobernación se conservan algunos informes sueltos sobre la situación en Alemania, Italia; pero otros informes de la misma época se encuentran en el archivo de Exteriores: Entre 1887 y 1897 el ministerio de Estado centra especialmente su atención en los avances que se están haciendo en Alemania ${ }^{23}$.

Destaca especialmente la información remitida en julio-agosto de 1894 por las embajadas de Alemania y Austria sobre la legislación de accidentes

\footnotetext{
21 Vid. el discurso de Dato en la academia de Ciencias Morales y Políticas, La Justicia social, 1910 y el de Canalejas en la Academia de Jurisprudencia de Madrid... El libro de A. Buylla La cuestión obrera y las leyes se publicó antes por entregas en la Rev. gen. de Legislación y Jurisprudencia". Referencia a los congresos internacionales de accidentes de trabajo y de seguros obreros en F. Montero Origenes y antecedentes de la previsión social, Madrid, 1988, pp. 38 y ss.

22 Para todo este tema, la biblioteca del Ministerio de Trabajo (antigua biblioteca del IRS) conserva una buena colección de revistas y boletines, órganos de las instituciones reformistas análogas que mantenian correspondencia con el IRS español.

Sobre la Sección española de la Asociación Internacional para la protección legal de los trabajadores, vid. sus publicaciones, especialmente sus memorias anuales.

23 Con fecha 31 de mayo de 1887 el embajador en Berlín, conde Benomar, "remite una relación completa clasificada de las leyes y proyectos sobre seguros de los trabajadores y obreros alemanes". La comunicación oficial sobre los acuerdos adoptados en la Conferencia de Berlín de 1890 llegó al Ministerio de Estado, y desde hai fue remitida a Gobernación... AMAE, Politica, leg. 2.787-2.790.
} 
de trabajo y seguros obreros, en un momento en que la CRS y el ministro Alberto Aguilera preparaba un proyecto para España: «el gobierno español - decía la orden cursada a los diplomáticos españoles- desea conocer con la brevedad posible tanto la legislación como los medios que en la práctica se usen en ese país par aprevenir los accidentes de trabajo y asegurar la suerte de los obreros inutilizados por enfermedad, por edad o por accidente (...) Si se hubiere celebrado Congresos como el de París en 1889 o el de Berna en 1891 convendría citarlos y acompañar las conclusiones" ${ }^{24}$. Un poco más tarde, la creación del Consejo Superior de Protección a la Infancia va acompañado de una encuesta a los embajadores solicitada por el propio consejo al Ministerio de Estado ${ }^{25}$.

Una parte de la política social se intentó canalizar a través de la politica educativa, de acuerdo con el enfoque reformista que compartían tanto los institucionistas como los católicos, aunque sobre supuestos y prototipos morales distintos. Por eso también algunos fondos de Educación, los que se refieren a la subvención de las iniciativas escolares populares, o los intentos de desarrollar la formación profesional, interesan al estudio de la reforma social desde otra perspectiva ${ }^{26}$.

\section{Archivos provinciales y municipales. Historia local}

El importante auge de la historia local en los últimos años es objeto, como se sabe, de valoraciones contrapuestas. Sin negar los riesgos y limitaciones de este tipo de estudios, sobre todo si no se sitúan en un marco teórico adecuado, no se puede negar su virtualidad y hasta su necesidad, especialmente para el estudio de algunas parcelas. Precisamente los estudios más

24 Real Orden de 21-VI-94, a los representantes de España en Londres, París, Berlín, Roma, Viena, Lisboa, Berna, Holanda y Suecia y Noruega, y cónsul en Berna. La respuesta deberia ser remitida antes del 1 de agosto. Se conservan los informes sobre Suecia y Noruega, una memoria muy extensa del primer secretario de embajada en Paris que incluye como apéndice una selección de textos legales; otras también extensas de Alemania, Austria, de inglaterra, de Suiza (el cónsul en Berna), de Portugal. AMAE, Politica, leg. 2.787-2.790.

25 Con fecha 9-12-1909 el secretario general del Consejo, el médico Manuel Tolosa Latour, agradecia al subsecretario del $M^{\circ}$ de Estado el envio de diversos documentos "relacionados con el requerimiento hecho a ese Ministerio para que los representantes de España en el Extranjero envien cuantas noticias, proyectos y leyes se publiquen en las diversas naciones relacionadas con la protección a la infancia y represión de la Mendicidad"; se citan despachos desde Suiza, Inglaterra, Austria, Centro América, Francia, Bélgica, Perú, que remiten leyes y reglamentos, AMAE, Politica, leg. 2.787-90.

26 $\quad$ AGA, M $M^{\circ}$ Educación, leg. 6.647 a 6.661 , Subvenciones a establecimientos de enseñanza no oficiales. 
renovadores sobre beneficiencia o sobre conflictividad social y movimiento obrero se han hecho en ese ámbito de la historia local y regional.

Como ya se ha señalado, para nuestro tema es fundamental la documentación de las Juntas provinciales y municipales de reformas sociales, así como la correspondencia de los presidentes de esas Juntas, alcaldes y gobernadores. Varias investigaciones locales han demostrado la utilidad de esa documentación para reconstruir las características y el alcance del conflicto social; las resistencias en la aplicación de la legislación social; el grado de participación de las fuerzas sociales, obreros, patronos, en esos incipientes organismos de conciliación y arbitraje.

En la búsqueda y catalogación de esa documentación ha de tenerse en cuenta el reflejo sobre la administración local y provincial de los cambios en la administración central: después de 1924, las "delegaciones de trabajo vienen a sustituir a las juntas de reformas sociales".

Además de estos organismos directamente vinculados a la gestación de la política social hay que tener en cuenta la documentación de otras juntas fronterizas, como las de beneficiencia, educación, sanidad, protección de menores (después de 1914).

La deficiente conservación y catalogación de la documentación de los gobiernos civiles, sólo parcialmente trasvasada a los archivos históricos provinciales, hace mucho más difícil su consulta que en el caso de los archivos municipales ${ }^{27}$.

Los fondos archivisticos de las diputaciones provinciales, generalmente mucho mejor conservados y accesibles, son fundamentales especialmente para el estudio de las instituciones benéficas y la aplicación, en el nivel provincial, de la política asistencial y sanitaria.

Entre los archivos privados institucionales, que contienen fondos relacionados con el tema, hay que mencionar los de las Cajas de Ahorros, los de las Cámaras agrarias y de industria y comercio, las asociaciones patronales y obreras, las empresas, los de la Iglesia y las asociaciones católicas ${ }^{28}$.

27 Recientemente lo estamos comprobando en un intento de llenar una laguna documental sobre estadisticas de asociaciones en 1887, 1890 y 1900 , sólo parcialmente conservadas en los archivos centrales de Gobernación (AHN y AGA). Las respuestas de los archivos históricos provinciales manifiestan la ausencia de documentación de los gobiernos civiles entre sus fondos.

${ }_{28} \mathrm{Vid}$. la relación de fuentes para el estudio de las «relaciones laborales» que incluye 1. Olabarri en "Metodología de la historia de las relaciones laborales en el ámbito local" en "Lucha de clases o conflictos de intereses". Ensayos de Historia de las relaciones laborales", pp. 163167, ed. Eunsa, Pamplona, 1991. También incluye un "Cuestionario-guia para el investigador", indice completo y útil de temas a estudiar. 
De la Beneficiencia a la reforma social. Los origenes de la política social...

En cuanto a los archivos de particulares, se trataria sobre todo de localizar los archivos o biblioteca personales de políticos, propagandistas, inspectores de trabajo, pioneros de la reforma social, etc. Piénsese, por ejemplo en la importancia de Balbás para la Guipúzcoa, o de Moragas para Cataluña ${ }^{29}$.

ig Sobre Moragas, vid. la biografía de A. Pérez Bastardas op. cit. Sobre la Caja de Guipuzcoa y Balbás hay una tesis doctoral de Ascensión Martinez a punto de leerse en la UNED. 